\title{
The fallacy of 'alternative' medicine
}

A company founded by Prince Charles was reprimanded by UK regulators earlier this year for making unsubstantiated claims about the efficacy of three of its herbal remedies. The Advertising Standards Authority ruled that promoting the Echinacea, Hypericum and 'Detox' tinctures as "alternative and natural ways of treating common ailments such as colds, low moods and digestive discomfort" was misleading. Earlier, the Medicines and Healthcare products Regulatory Agency (MHRA)-the UK's equivalent of the US FDA-had ordered the company to remove from its website a statement about two of the remedies assuring customers that they had been assessed in terms of safety, quality "and efficacy".

These events might reflect confusion about the controversial new MHRA scheme under which two of the preparations had been licensed, which dictates that 'traditional use' is sufficient to grant a herbal product the right to be marketed, regardless of efficacy. Worryingly, however, the right of companies to make claims about such unproven treatments could even be protected by law in future-at least in the UK-if the British Chiropractic Association (BCA) has its way. The BCA has accused the respected science writer Simon Singh of libel for writing in The Guardian that it "happily promotes bogus treatments." This case, awaiting hearing at the time of going to press, threatens to set a dangerous precedent that restricts freedom of speech to criticize so-called 'alternative' therapy.

The term 'alternative,', complementary' or 'integrative' medicine has no clear or consistent definition, but is used to corral together a group of disparate treatments including homeopathy, reflexology, massage therapy, acupuncture and herbalism. A 2007 survey by the NIH revealed that almost 4 out of 10 adults in the US use one or other of these approaches, mainly to treat musculoskeletal complaints. Although kidney disease is not a common reason for use of 'alternative' therapies, affected patients are particularly susceptible to the ill effects of some of these treatments. Indeed, many traditional remedies can cause kidney damage-the most notorious example being the progressive fibrosis caused by Chinese herb preparations containing extracts of plants from the genus Aristolochia. Herbal medicines can also harm renal patients indirectly by interacting with or prompting discontinuation of prescribed drugs.

Yet 'alternative' medicine has come to be regarded as a sacred cow, exempt from the rigors of scientific testing and regulation. Somehow, 'alternative' is automatically perceived to mean 'natural' and 'nontoxic'; crucially, the name also seems to imply that treatments such as homeopathy should be judged differently to medicines that originate in the test tubes of pharmaceutical companies. This argument is analogous to the evolutionary biologist Stephen Jay Gould's concept of science and religion as 'non-overlapping magisteria' that cannot be pitted against each other, an idea that is convenient as it is flawed. Just as religious believers cannot simply ignore scientific truths, proponents of 'alternative' medicine cannot claim that the utility of this approach lies outside rational measures of clinical efficacy.

As many as two-thirds of the people who use 'alternative' medicine don't tell their doctor about it; equally, many doctors are reluctant to enquire about the use of 'alternative' medicine, believing perhaps that such treatments are a harmless means of harnessing the placebo effect. However-besides the fact that the cost of many 'alternative' treatments vastly exceeds that of a simple sugar pill—-to adopt such a "don't ask, don't tell" approach is to leave patients at risk of avoidable kidney damage and to silently collude with those organizations, companies and individuals who seek, either deliberately or not, to convince patients that there is a genuine alternative to evidence-based treatment. Questioning patients about all the medicines they are taking, both prescribed and unprescribed, is an essential part of any nephrology consultation.

'Alternative' medicine is a pernicious misnomer. 'Alternative' treatments are no more natural, effective or safe than 'conventional' ones; in many cases, they are quite the reverse. "So-called alternative therapies need to be assessed and then classified as good medicines or bogus medicines," argues Singh in his book 'Trick or Treatment? Alternative Medicine on Trial', co-written with Edzard Ernst, Professor of Complementary Medicine at the University of Exeter. "Hopefully, in the future, the good medicines will be embraced within conventional medicine and the bogus medicines will be abandoned." Some therapeutic practices that were once labeled 'alternative', such as cognitive behavioral therapy, have already made the transition to the mainstream. As one comedian wryly observes, "You know what they call alternative medicine that's been proven to work? Medicine". Prince Charles, take note.

doi:10.1038/nrneph.2009.96

\section{As many as two-thirds of the people who use 'alternative' medicine don't tell their doctor about it... 77}

Chloë Harman is the Editor of Nature Reviews Nephrology.

Competing interests The author declares no competing interests. 